\title{
Numerical Simulation and Analysis of Flow-Field in Rotating Rectangular Passage
}

\author{
X. L. Wei ${ }^{1,2 *}$ \\ ${ }^{1}$ College of Mechanical Science and Engineering, Ji Lin University, Changchun 130022, China \\ ${ }^{2}$ Department of Aeronautic Mechanical Engineering, Aviation University of Air Force, Changchun \\ 130022, China \\ Email: wei411036@163.com
}

\begin{abstract}
Applying the finite volume method, the air flow field in a straight passage with a rotating coordinate system is simulated in case the passage is rotating as a whole and also the case that upper wall remaining stationary and the other 3 rotating at arbitrary speeds. The SST turbulence model and the RSM model are utilized to solve these problems respectively. For the case all walls rotating simultaneously, comparisons between the present calculation results with the test data quoted from reference literature are made. Agreements with experimental data are good .It is found that the results by the SST turbulence model are closer to the test data than those by the RSM model. The SST model is selected to calculate the case only part of walls rotating, after taking into account the amount of computation. The results show that the peak velocity of mainstream also leans to the pressure side, but the eddy is continuously formed near the pressure side and the top wall, and drifts towards the lower wall at lower rotation $(100 \sim 300 \mathrm{rpm})$. At higher rotation $(600 \sim 2000 \mathrm{rpm})$, the peak velocity of mainstream is moved to the suction side and the lower wall, the vortices are increased in number, the distribution of velocity along the height and breadth is no longer symmetric. The current exhibits strong three-dimensional characteristics.
\end{abstract}

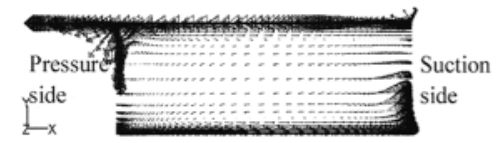

(a) $100 \mathrm{rpm}$

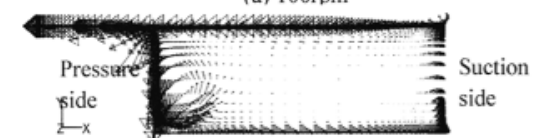

(c) $600 \mathrm{rpm}$

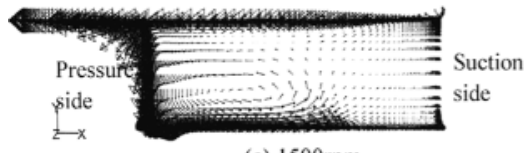

(e) $1500 \mathrm{rpm}$

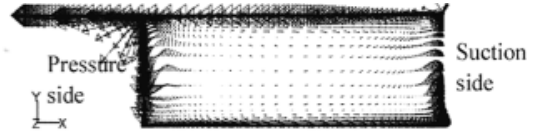

(b) $300 \mathrm{rpm}$

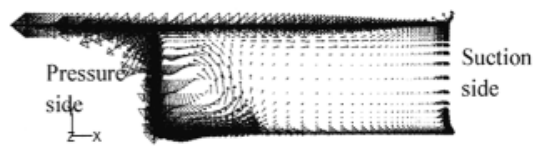

(d) $1000 \mathrm{rpm}$

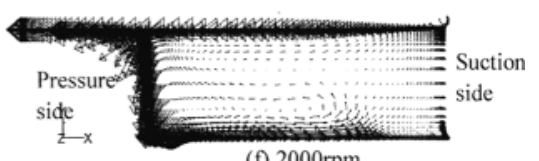

(f) $2000 \mathrm{rpm}$

Figure: Velocity vector on the $z=610 \mathrm{~mm}$ cross-section in case the upper wall is fixed

\section{REFERENCES}

1. Wanger R E, Velkoff H R. Measurements of secondary flows in a rotating duct. Journal of Engineering for Power, 1972; 94(10): 261-270

2. Liu L J, Xı Z, Shi F. Numerical analysis of flow-field in rotating duct at arbitrary speeds. Acta Aeronautica Et Astronautica Sinica, 1996; 17(4): 385-390 